\title{
The Order Quantity Decision of Newsboy Retailer with Financing
}

\author{
Zhonghua MA \\ School of Management \& Economic, Shanghai Maritime University, Shanghai 201306, China \\ E-mail:zhma@shmtu.edu.cn
}

\begin{abstract}
We analyze the retailer's optimal order with capital constraint under stochastic demand. We consider the impact of external financing, that is inventory financing, and the internal financing, that is trade credit, on the order strategy of retailer separately. We establish revenue model of retailer and solve, and give revenue of retailer and supplier respectively. Finally, we give the impact of own funds on the retailer's order quantity, retailer's revenue, supplier's revenue, as well as the impact on the overall revenue gains of the supply chain. And some analysis and statement are also given in the end.
\end{abstract}

Keywords inventory financing; trade credit; newsboy model

\section{Introduction}

Supply chain is composed of multiple independent enterprises, because each node enterprise's object is to maximize its own revenue, the decisions will have effect on the profit of the supply chain. And in the actual process of economic operation, retailers will often not realize the optimal order quantity because of shortage of funds, where the retailer cannot realize the optimal order quantity of its own based on market demand will not only impact the retailer, but also impact the supplier and supply chain's overall revenue.

Supply chain management with capital constraint research has made some achievements. Buzacott and Zhang ${ }^{[1]}$ proved external financing for enterprises development has a great role in promoting under the assumption that some of the fledgling companies to finance all of its assets as collateral. Xu \& Birge ${ }^{[2]}$ studied newsboy type of business in case of shortage of funds will reduce inventory investment with the risks of demand uncertainty. Data and $\mathrm{Hu}^{[3]}$ analysed the inventory management strategy based on the classical newsboy model with financial constraints. Chen, etc. ${ }^{[4]}$ studied the retailer access to financing from the capital market in order to achieve their optimal procurement strategy with the existence of financial constraints. Zhang and Chen ${ }^{[5]}$ considered pledge funding constraints and financing models for inventory decisions.

There are also some research results on supply chain coordination contract under trade credit. Jaber ${ }^{[6]}$ considered a supply chain taking into account the supply chain coordination and distribution of interests under trade credit. Chen ${ }^{[7]}$ established a supply chain taking

Received October 31, 2013, accepted March 17, 2014

Supported by MOE of Humanities and Social Science (11YJC630153); Science \& Technology Program of Shanghai Maritime University (20120084); Shanghai Science and Technology Development of Soft Science Research Project (12692108200); Construction Project of Shanghai Maritime University Graduate Course Emphasis; Shanghai Maritime University Graduate Curriculum 
into account the savings and distribution problems under trade credit. Sarmah ${ }^{[8]}$ considered suppliers and retailers with independent revenues under the trade credit.

Inventory financing is proposed by Luo and $\mathrm{Zhu}^{[9]}$. Chen and Zhu ${ }^{[10]}$ divided FTW into three modes according with the risks involved in business operations and the funding needs. Li, etc. ${ }^{[11]}$ considered pledge rate decision of banks pledged inventories for the price stochastic fluctuations in inventory. $\mathrm{Li}$ and $\mathrm{Xu}^{[12]}$ analyzed the stages of the loan is to control and reduce the risk of moral hazard. Chen and $\mathrm{Zhu}^{[13]}$ studied financing and operation of a supply chain with a supplier and a newsboy retailer.

We study a two-stage supply chain with a supplier and a newsboy retailer, and the retailer faces funds shortage which can obtain finance through trade credit or inventory financing. We analyze the optimal ordering policy and its impact on retailer's profit and supplier income, under the conditions: no financing; trade credit; inventory financing.

\section{Symbols and assumptions}

Consider a two stage supply chain with a single supplier and a single retailer, the supplier supply goods to the newsboy retailer, and the retailer faces the final market. Suppose the supplier and the retailer are independent decision-makers, and the retailer decides order quantity to maximize income, the supplier accepts retailer's order with no production capacity limit.

The production cost of supplier with enough funds is $C_{s}$, the wholesale price is $w, w>C_{s}$. The retailer faces the final market, and the retail price is $p$, which satisfies $p>w$. The market demand $x$ is stochastic, with density function $f(x)$ and distribution function $F(x)$. The retailer is newsboy style, the salvage value of the unsold goods in the end of the period is $C_{0}$. The cost of lost sale is not considered, and the retailer's own funds is $B$.

The retailer's order quantity is $Q$ with enough funds, and the revenue function of the retailer is

$$
R(Q)=(p-w) Q \int_{Q}^{\infty} f(x) \mathrm{d} x+(p-w) Q \int_{0}^{Q} f(x) \mathrm{d} x-\left(w-C_{0}\right) \int_{0}^{Q}(Q-x) f(x) \mathrm{d} x-w Q r_{0}
$$

where the last term is the cost of capital, that is with the order quantity $Q$, the cost is $w Q$. And the risk free rate is $r_{0}$. In fact, only when the benefits of the retailer to sell products is larger than fixed deposit interest of investment funds, the retailer will be order from the supplier. Also, consider the cost of capital also contributes funding constraints, and then analyze different financing models to retailers ordering strategy.

The retailer determine order quantity to maximize the revenue $R(Q)$, then

$$
R(Q)=(p-w) Q(1-F(Q))+(p-w) \int_{0}^{Q} x f(x) \mathrm{d} x-\left(w-C_{0}\right) \int_{0}^{Q}(Q-x) f(x) \mathrm{d} x-w Q r_{0}
$$

and $\frac{\mathrm{d} R(Q)}{\mathrm{d} Q}=(p-w)(1-F(Q))-\left(w-C_{0}\right) F(Q)=0$, further more $F(Q)=\frac{\left(p-w-w r_{0}\right)}{\left(p-C_{0}\right)}$, the optimal order quantity of retailer is $\hat{Q}=F^{-1}\left(\frac{p-w-w r_{0}}{p-C_{0}}\right)$.

The optimal order quantity is $\hat{Q}$, when the retailer has enough funds $B$, and satisfies $B>$ $w \hat{Q}$. While when the retailer with capital constraints in order $B<w \hat{Q}$, the retailer's order 
quantity is $\frac{B}{w}$. So the optimal order quantity of the retailer is

$$
\hat{Q}^{\prime}= \begin{cases}F^{-1}\left(\frac{p-w-w r_{0}}{p-C_{0}}\right), & B \geq w Q \\ \frac{B}{w}, & B<w Q\end{cases}
$$

Notice the cost of capital for the order quantity $w Q r_{0}$, so when the retailer can gain more revenue from other channel, the order quantity will decrease. And from the expression (1), we can know when $r_{0}$ is large enough, the order quantity will decrease, and when $R\left(Q^{\prime}\right) \leq 0$, the order quantity is zero.

With the price and quantity contract between the supplier and the retailer, the retailer decides the order quantity $Q$ under the wholesale price $w$, and the profit of supplier is

$$
\pi\left(\hat{Q}^{\prime}\right)=\left(w-C_{s}\right) \hat{Q}^{\prime}
$$

Similar with (1), the optimal order quantity to maximize the whole supply chain profit is $\hat{\hat{Q}}=F^{-1}\left(\frac{p-C_{s}-C_{s} r_{0}}{p-C_{0}}\right)$.

\section{$3 \quad$ Ordering strategy of retailer}

\subsection{Inventory financing}

With own capital constraint, the retailer order quantity will be $\frac{B}{w}$, and get funds through inventory financing, with the pledge rate $\delta$, and financing rate $r_{B}$. The retailer can use funds to order more goods, assuming pledge financing and re-order are completed before the end of the sales cycle. The retailer's profit is

$$
\begin{aligned}
R_{s}(Q)= & (p-w) Q \int_{Q}^{\infty} f(x) \mathrm{d} x+(p-w) \int_{0}^{Q} x f(x) \mathrm{d} x-\left(w-C_{0}\right) \int_{0}^{\frac{\delta B}{w}}\left(\frac{\delta B}{w}-x\right) f(x) \mathrm{d} x \\
& -(w-\delta w) \int_{\frac{\delta B}{w}}^{Q}(Q-x) f(x) \mathrm{d} x-B r_{0}-\left(Q-\frac{B}{w}\right) w r_{B}
\end{aligned}
$$

We consider the inventory financing here, when the demand is less than $\frac{\delta B}{w}$, the salvage of the unsolved goods at the end of the cycle is $C_{0}$, and when the demand is larger than $\frac{\delta B}{w}$, but less than order quantity $Q$, the salvage of the unsolved goods is $\delta w$. The cost of capital concludes two parties: one is the cost of retailer's own capital $B r_{0}$, another is the cost of inventory financing $\left(Q-\frac{B}{w}\right) w r_{B}$.

From the profit of retailer, we have

$$
R_{B}^{\prime}(Q)=p-w-(p-w) F(Q)-(w-\delta w) F(Q)+(w-\delta w) F\left(\frac{B}{w}\right)-w r .
$$

And the optimal order quantity of retailer is $\hat{Q}_{B}=F^{-1} \frac{\left(p-w-w r_{B}+(w-\delta w) F\left(\frac{B}{w}\right)\right)}{(p-\delta w)}$, which is related with own capital $B$, inventory financing pledge rate $\delta$, and financing rate $r_{B}$. The optimal order quantity $\hat{Q}_{B}$ is larger than the own capital quantity and less than that with enough funds, that is $\frac{B}{w} \leq \hat{Q}_{B}<\hat{Q}$. If the financing amount is large enough to satisfy the optimal quantity of retailer, that is $\frac{\delta B}{w} \geq \hat{Q}_{B}-\frac{B}{w}$, the profit of retailer is above and the interest of financing is $\left(Q_{L}-\frac{B}{w}\right) w r$. We have:

1. The optimal order quantity $\hat{Q}_{B}$ decreases with rate $r, \frac{B}{w} \leq \hat{Q}_{B}<\hat{Q}$. 
2. When $\delta B$ is large enough, and satisfies $\delta B+B>w \hat{Q}_{B}$, the optimal quantity of retailer $\hat{Q}_{B}$ will increase with $B$, but with the cost of its own funds $r_{0}$ and the salvage value of goods $C_{0}$ unrelated.

3. When the own funds of retailer $B$ is small, the order quantity of retailer will decrease with $B$. The reason is that when $\delta B+B<\hat{Q}_{B}$, the optimal order quantity of retailer is $\frac{\delta B+B}{w}$, which will decrease with $B$.

With inventory financing, the optimal order quantity of retailer satisfies

$$
\hat{Q}_{B}^{\prime}= \begin{cases}F^{-1}\left(\frac{p-w-r_{B} w+(w-\delta w) F(B / w)}{p-\delta w}\right), & \delta B+B \geq w \hat{Q}_{B} \\ \frac{\delta B+B}{w}, & \delta B+B<w \hat{Q}_{B}\end{cases}
$$

And the profit of supplier is

$$
\pi_{B}\left(\hat{Q}_{B}^{\prime}\right)=\left(w-C_{s}\right) \hat{Q}_{B}^{\prime}
$$

\section{$3.2 \quad$ Trade credit}

The supplier provides trade credit to the retailer, and the retailer pays back at the end of the sale cycle. The retailer's profit is

$$
R_{T}(Q)=(p-w) Q \int_{Q}^{\infty} f(x) \mathrm{d} x-\left(w-C_{0}\right) \int_{0}^{Q}(Q-x) f(x) \mathrm{d} x+(p-w) \int_{0}^{Q} x f(x) \mathrm{d} x-B r_{0}
$$

From the above expression, we can see that the cost of capital of the retailer is the cost of its own capital $B$. Let the derivative of $R_{T}(Q)$ be zero, we can have the optimal order quantity of the retailer is

$$
\hat{Q}_{T}=F^{-1}\left(\frac{p-w}{p-C_{0}}\right)
$$

where the optimal order quantitative is independent with the retailer's own capital.

Notice that $w\left(1+r_{0}\right)>w>C_{s}$, that is the retailer's profit must be positive, with the expression of $\hat{Q}_{B}, \hat{Q}, \hat{Q}_{T}, \hat{\hat{Q}}$, it is easy to have $\hat{Q}_{B}<\hat{Q}<\hat{Q}_{T}<\hat{\hat{Q}}$. The order quantity of the retailer under trade credit is less than the optimal order quantity, but is larger than that under inventory financing and capital constraint. In the situation that the trade credit rate is zero, the supplier's profit is $\left(w-C_{s}\right) \hat{Q}_{T}-\left(w \hat{Q}_{T}-B\right) r_{0}$, the last term is the cost of capital.

In trade credit, the supplier will only provide trade credit to the retailers that have longterm cooperation relationship. The supplier can control the financing risk better, and retailers will not keep promise only when the total sales less than the loan, that is demand is less than $\frac{w \hat{Q}_{(}(T-B)}{p}$, the retailer will pay back supplier with all the sales and the savage of goods. So the supplier's profit is

$$
\begin{aligned}
\left(1-F\left(\frac{w \hat{Q}_{T}-B}{w}\right)\right)\left(\left(w-C_{s}\right) \hat{Q}_{T}-\left(w \hat{Q}_{T}-B\right) r_{0}\right) & +p \int_{0}^{\frac{w \hat{Q}_{T}-B}{p}} x f(x) \mathrm{d} x \\
& +C_{0} \int_{0}^{\frac{w \hat{Q}_{T}-B}{p}}\left(\hat{Q}_{T}-x\right) f(x) \mathrm{d} x
\end{aligned}
$$

And in practice the relationship is right, $C_{s} \leq C_{0}<w$, so long as the retailer pay back with all the sales and the salvage value of goods, the losses can be avoided. Suppose the financing rate 
of trade credit is $r_{T}$, and satisfies $r_{T}>r_{0}$, the retailer's profit is

$$
\begin{aligned}
R_{T}(Q)= & (p-w) Q \int_{Q}^{\infty} f(x) \mathrm{d} x-\left(w-C_{0}\right) \int_{0}^{Q}(Q-x) f(x) \mathrm{d} x \\
& +(p-w) \int_{0}^{Q} x f(x) \mathrm{d} x-\left(Q-\frac{B}{w}\right) w r_{T}-B r_{0}
\end{aligned}
$$

Similar with the above analysis, we can have the optimal order quantity is

$$
\hat{Q}_{T}^{\prime}=F^{-1}\left(\frac{p-w-w r_{T}}{p-C_{0}}\right)
$$

And the profit of the supplier is

$$
\pi_{T}\left(\hat{Q}_{T}^{\prime}\right)=\left(w-C_{s}\right) \hat{Q}_{T}^{\prime}-\left(w \hat{Q}_{T}^{\prime}-B\right) r_{0}
$$

\section{Example}

Consider a swimsuit supply chain with a supplier and a retailer. In the coming summer, swimsuit retailer faces uniform distribution demand, and the density function is $f(x)=\frac{1}{b-a}$, the distribution function is $F(x)=\frac{x-a}{b-a}$.

The production cost of supplier with enough funds is $C_{s}=\$ 300$, and the wholesale price is $w=\$ 500$. The retail price is $p=\$ 1000$, which is decided by the market. At the end of summer, the salvage value of the unsolved swimsuit is $C_{0}=\$ 400$. The cost of the retailer's own funds $B$ is $r_{0}=4 \%$. When the retailer's own funds can not satisfy the optimal order quantity, there are two ways for the retailer to finance, one is inventory financing with pledge rate $\delta=0.6$ and financing rate $r_{B}=10 \%$, the other is trade credit with financing rate $r_{T}=5 \%$.

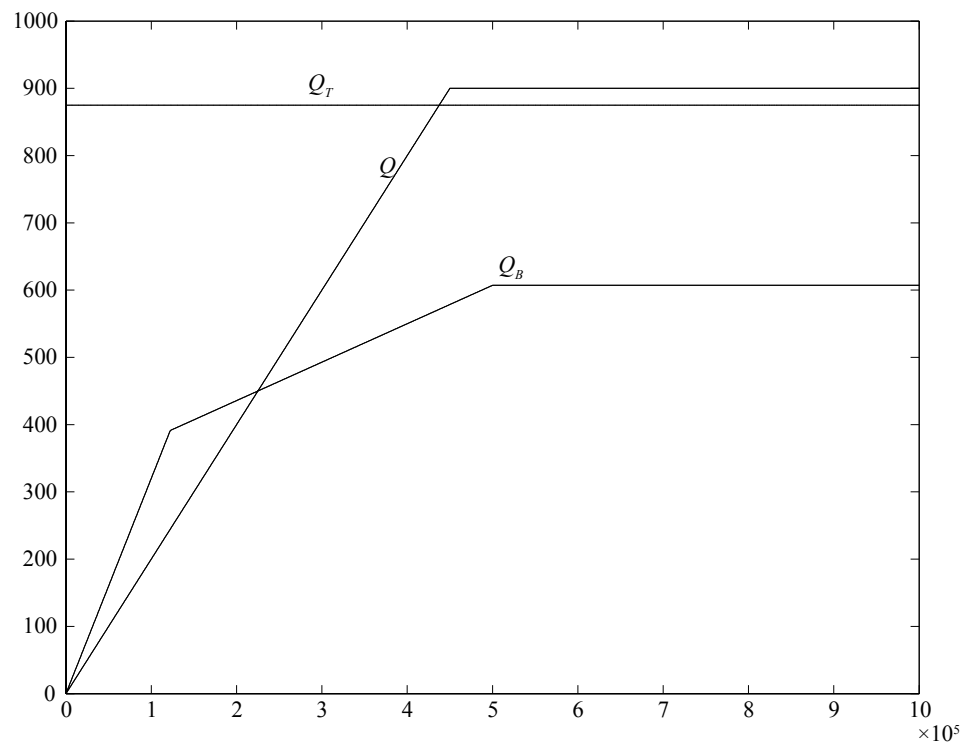

Figure 1 Retailer's own funds on order quantity

In Figure 1 we give the optimal order quantity when the number of the retailer's own funds $B$ changes from 0 to 100000 . Without financing, based on the result of (2), the retailer realized the order with all the own funds though it is not enough (from $\$ 0$ to $\$ 450000$ ), and the optimal order quantity realizes when the retailer's own funds is enough (larger than $\$ 450000$ ). With 
inventory financing, based on the result of (5), we give the optimal order quantity $Q_{B}$ which changes with its own funds $B$, and the optimal order quantity increases with its own funds, but less than that with enough own funds. The inventory financing is more useful for those retailers without enough own funds. With trade credit, from the results of (8) and (11), the retailer's optimal order quantity $Q_{T}$ is not affected by the own funds.

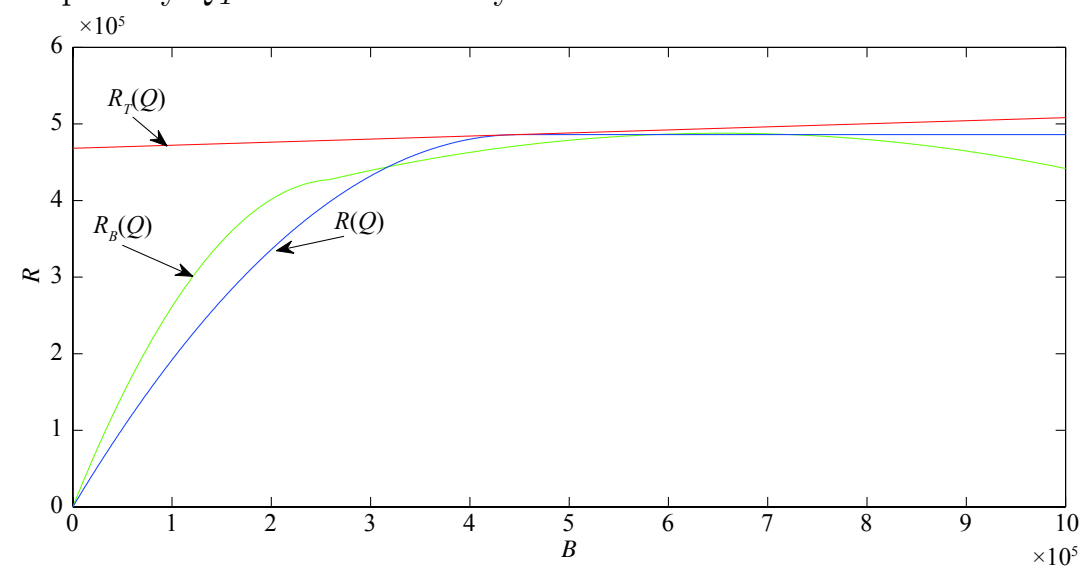

Figure 2 Retailer's own funds on its profit

In Figure 2 we give the retailer's profit $R$ changes with its own funds $B$ from $\$ 0$ to $\$ 100000$. Without financing, from the result of (1), the retailer orders with all its own funds (from $\$ 0$ to $\$ 450000$ ), and the profit increases with the retailer's own funds. The retailer realizes the optimal order quantity when its own funds is enough (larger than $\$ 450000$ ), and the profit of retailer is largest. With inventory financing, from the result of (4), we give the profit of retailer $R_{B}(Q)$ changes with its own funds $B$. The order quantity and profit increase with its own funds. But for the cost of inventory financing, the profit will decrease after it reaches the maximum. With trade credit, from the result of (7) and (10), the profit of retailer $R_{T}(Q)$ increases with its own funds.

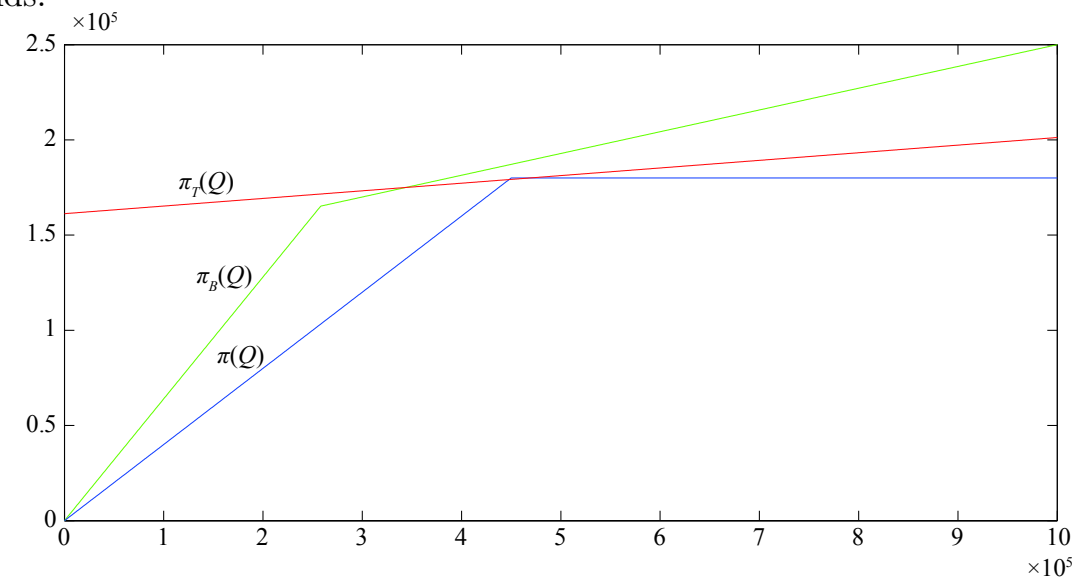

Figure 3 Retailer's own funds on supplier's profit

In Figure 3 we give the profit of supplier $\pi$ changes with the retailer's own funds $B$ (from $\$ 0$ to $\$ 100000)$. Without financing, from the result of (3) we can see the profit of supplier increases with the retailer's own profit. And the profit of supplier reaches the maximum when 
the retailer has enough own funds, so it is reasonable for the supplier to provide financing to the retailer without enough own funds. With inventory financing, from the result of (6) we give the profit of supplier changes with the retailer's own funds. And the profit of supplier increases with the retailer's own funds, and will reach the maximum of the supply chain coordination for its riskless of inventory financing. With trade credit, from the result of (9) and (12) we can see the profit of supplier increases slowly with the retailer's own funds. But for the supplier provides financing to the retailer $\left(r_{T}=0\right.$ or $\left.r_{T} \neq 0\right)$, the profit of supplier is lower than that with inventory financing.

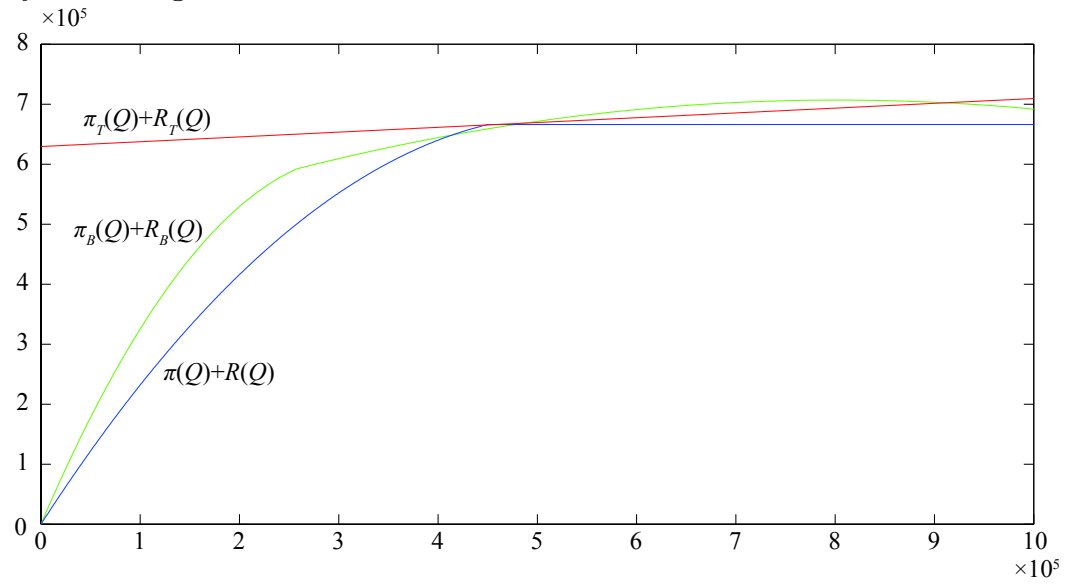

Figure 4 The retailer's own funds on the supply chain's profit

In Figure 4 we give the profit of supply chain $\pi+R$ which changes with the retailer's own funds (from $\$ 0$ to $\$ 100000$ ). Without financing, the profit of the supply chain is affected by the retailer's own funds, and increases until the retailer's own funds is enough for the optimal order quantity. At the same time, the profit of the supply chain increases for the financing, and trade credit is more effective than inventory financing.

\section{Conclusions}

In this paper we consider a supply chain consisting of a supplier and a retailer which newsboy type retailer faces a shortage of funds, supplier and retailer are seeking to maximize revenue. we give comprehensive analysis of the cases including without financing, inventory financing, trade credit, the retailer's order quantity and its impact on the revenue. Because of funding constraints, retailer in the case of no external financing can only rely on its own funds. Inventory financing commonly used, the retailer's order quantity will increase, as well as in trade credit which a pattern of internal financing the supply chain advantage. when the retailer's order quantity will not be bound by the number of its own funds, but also noted that the inventory financing, the bank assumed the related financing and market demand risks, under trade credit suppliers to assume more inventory risk. Finally, an example is given for different circumstances retailer order quantity, retailer revenue, supplier revenue, supply chain revenue with changes in the number of retailer own funds, and the results are a description and analysis. 


\section{References}

[1] Buzacott J A, Zhang R Q. Inventory management with asset-based financing. Management Science, 2004, 50: $1274-1292$.

[2] Xu X D, Birge J R. Joint production and financing decisions: Modeling and analysis. Working Paper, Graduate School of Business, University of Chicago, 2004.

[3] Dada M, Hu Q. Financing newsvendor inventory. Operations Research Letters, 2008, 36: 569-573.

[4] Chen X F, Zhu D L, Ying W J. Financing and operation decisions in budget constrained supply chain. Journal of Management Sciences in China, 2008, 11: 70-77.

[5] Zhang Y Y, Chen J B. Optimal inventory management under inventory financing. Systems Engineering Theory \& Practice, 2008, 28: 29-38.

[6] Jaber M Y, Osman I H. Coordinating a two-level supply chain with delay in payments and profit sharing. Computer \& Industrial Engineering, 2006, 50: 385-400.

[7] Chen L H, Kang K S. Integrated vendor buyer cooperative inventory model with variant permissible delay in payment. European Journal of Operation Research, 2007, 183: 658-673.

[8] Sarmah S P, Acharga D, Goyal S K. Coordination and profit sharing between a manufacturer and a buyer with target profit under credit option. European Journal of Operation Research, 2007, 182: 1469-1478.

[9] Luo Q, Zhu D L. A third-party logistics service innovation: Financing warehouse and its operation model. China Business and Market, 2002, 16: 11-14.

[10] Chen X F, Zhu D L. Innovation of logistics' finance service-finance logistics. Logistics Technology, 2005, 3: $4-6$.

[11] Li Y X, Xu Y, Feng G Z. On loan-to-value of inventory financing with doubly stochastics poisson default processes. Chinese Journal of Management Science, 2007, 15: 21-26.

[12] Li J, Xu Y, Feng G Z, et al. An optimal decision study on staged loaning in warehousing financing. Operations Research and Management Science, 2007, 16: 9-13.

[13] Chen X F, Zhu D L. System value of 3PL to the supply chain with capital constraints. Journal of Systems Engineering, 2008, 23: 666-673. 